\title{
Selection of Life Histories and its Adaptive Significance in a Snailfish Liparis tanakai from Sendai Bay
}

\author{
Tsuyoshi KaWASAKI ${ }^{* 1}$, Hiroaki HaShimoto*1, Hitoshi HondA ${ }^{* 1}$, \\ and Atsushi OTAKE*2
}

(Accepted July 9, 1982)

\begin{abstract}
Growth rate of snailfish is very high, eggs produced in late December-January becoming $400 \mathrm{~mm}$ in body length for male and $320 \mathrm{~mm}$ for female in the same period of the next year, and their life span is one year. Food habits shift from "number selection" depending mainly on crustaceans to "size selection" relying in particular on sandeel in October when growth is the fastest. Spawning seems to be carried out in several batches of eggs $1.4-1.5 \mathrm{~mm}$ across and the fertility is estimated to be a hundred thousand and tens of thousands. Snailfish supposedly raises the probability for eggs to survive through caring for them by their fathers. Short life of snailfish along with parental care for eggs brings about a rise of the intrinsic rate of natural increase $r_{m}$, resulting in an elaborate regulation of population numbers.
\end{abstract}

Snailfish Liparis tanakai is a demersal fish belonging to Liparidae, distributed widely around Japan and is said to be of northern cold water origin. Snailfish has no economic value and few papers other than AOYAMA ${ }^{1)}$ and KOSAKA ${ }^{23}$ have been published. In the present study we worked on the three elements, growth, reproduction and food habits, of snailfish in Sendai Bay*s located on the Pacific coast of northern Honshu, which provide life histories of the marine teleosts supporting the pattern of fluctuation in population, examined its strategy for survival, and revised the life historical triangle proposed by KAWASAKI. ${ }^{\text {s) }}$

"Growth" had been studied by all the authors and was written by KaWASAKI. "Reproduction" had been studied by HaSHMOTO and OTAKE and was written by the former. "Food Habits" had been worked on and was written by HONDA. "Discussion" was written by KAWASAKI based on scrutiny by the three authors exclusive of OTAKE.

Samples were obtained north of $37^{\circ} 50^{\prime} \mathrm{N}$ in Sendai Bay by trawling and gill netting by RV Suiko of Tohoku University, by gill netting by a chartered commercial boat, from a set net off Yuriage, Miyagi Pref., and at Haragama Fish Market, Fukushima Pref., for 1978-1981.

\section{Growth}

Body length*4 frequency histograms of samples for 1980 year class are given in the proceeding order in Fig. 1, indicating that length range of snailfish at a particular time is small and it is evident that size increases gradually with time. From this fact, OTAKE suggested that snailfish lives for one year.

Growth curves in length in Fig. 2 show that male snailfish grow faster than female after October when they have reached adult stage. Growth pattern is divided into four phases. Phase I lasts between early May and mid-July, showing a fairly fast growth. In phase II from mid-July to late September snailfish grow slowly. Phase III is a period of the fastest growth and is between early October and early November. In Phase IV of mid-November to mid-January snailfish again slower their growth. Growth rate (daily growth) and specific growth rate (growth rate divided by initial size) enclosed in Fig. 2 exhibit that snailfish of $90 \mathrm{~mm}$ in average in early May grow up to $400 \mathrm{~mm}$ for male and $320 \mathrm{~mm}$ for female in midJanuary of the next year.

Growth curves in weight in Fig. 3 reveal similar trends to those in length. Snailfish of $10 \mathrm{~g}$ in average in early May reach $1000 \mathrm{~g}$ for male and

*1 Faculty of Agriculture, Tohoku University, Sendai 980, Japan（川崎 健・㛢本博明・本多 仁：東北 大学農学部).

*2 Akita Prefectural Government, Honjo 015, Japan (大竹 敦：秋田県庁).

*3 Sendai Bay is here defined as the area from Oshika Peninsula south to Cape Shioyazaki and shallower than $150 \mathrm{~m}$ deep.

*4 Body length is a distance from the tip of the snout to the hindermost margin of the caudal fin. 

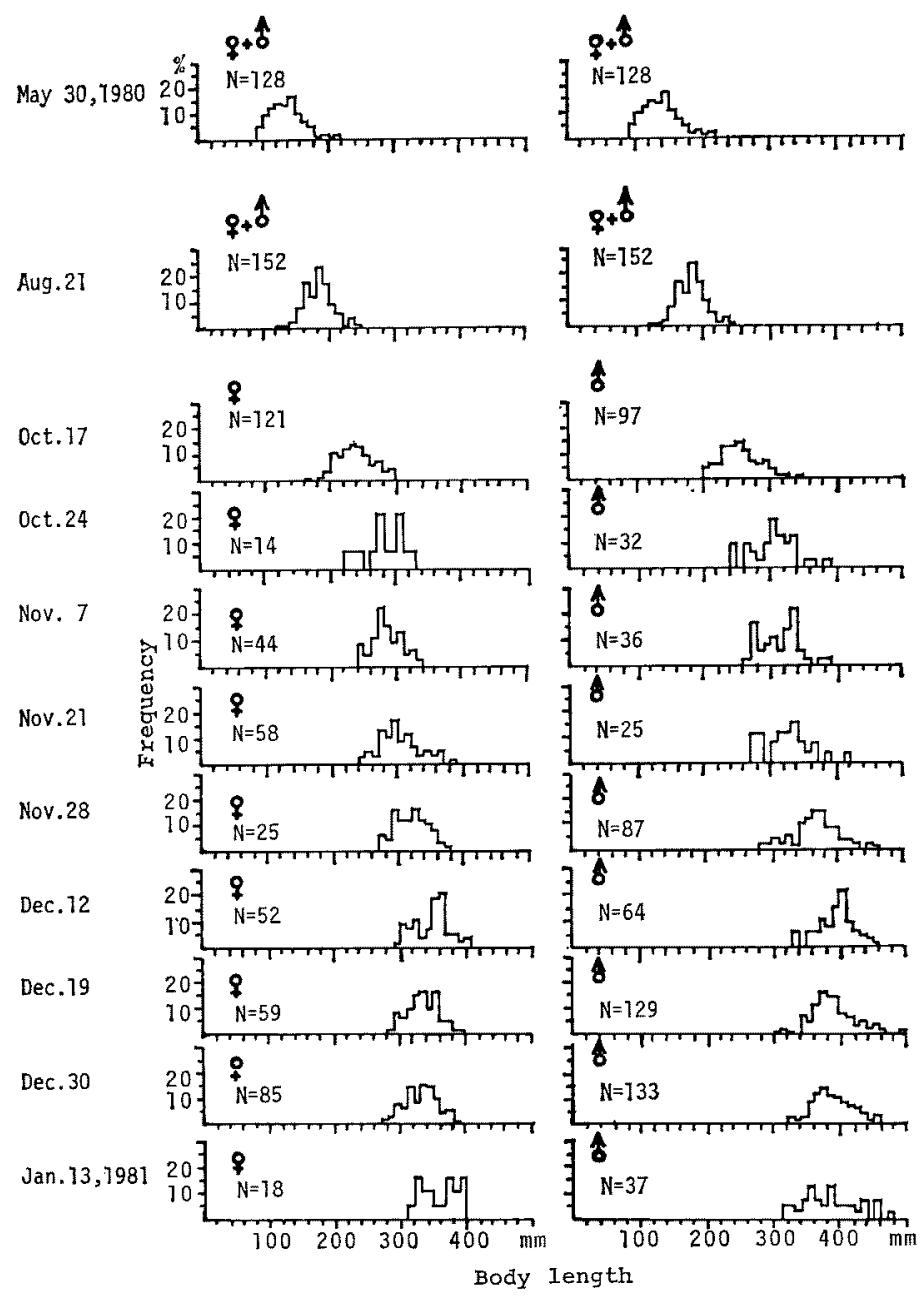

Fig. 1. Histograms of body length distribution in the advancing order for 1980 year class.

$500 \mathrm{~g}$ for female in next January, showing a large quantity of growth.

\section{Reproduction}

\section{Materials and Methods}

Gonads of snailfish for which sexing became possible were examined for 1978 and 1980 year classes. Gonads were weighed and oocyte diameter was measured to obtain frequency distributions. Number of eggs ovulated into the ovarian cavity was estimated by the gravimetric method. Number of developing oocytes on an ovarian lamella was also estimated by the same method. Since size distributions of the developing oocytes from several parts of an ovary were almost similar to one another, one ovarian lamella from the central part of an ovary was taken out to estimate the number of developing oocytes.

\section{Results}

Maximum GSI*-on-length curves (GSI curves) for 1980 year class are shown in the proceeding order in Fig. 4. Although GSIs of female had been lower than $3 \%$ before Nov. 2 , it rose to about $15 \%$ suddenly on Nov. 28 . While maximum GSIs had remained 20 to $25 \%$ level during December, they became $30 \%$ in January. On the other hand, male's GSIs were markedly lower as compared with those of female and remained under $3 \%$ through

* GSI is gonad weight as a percentage of body weight. 


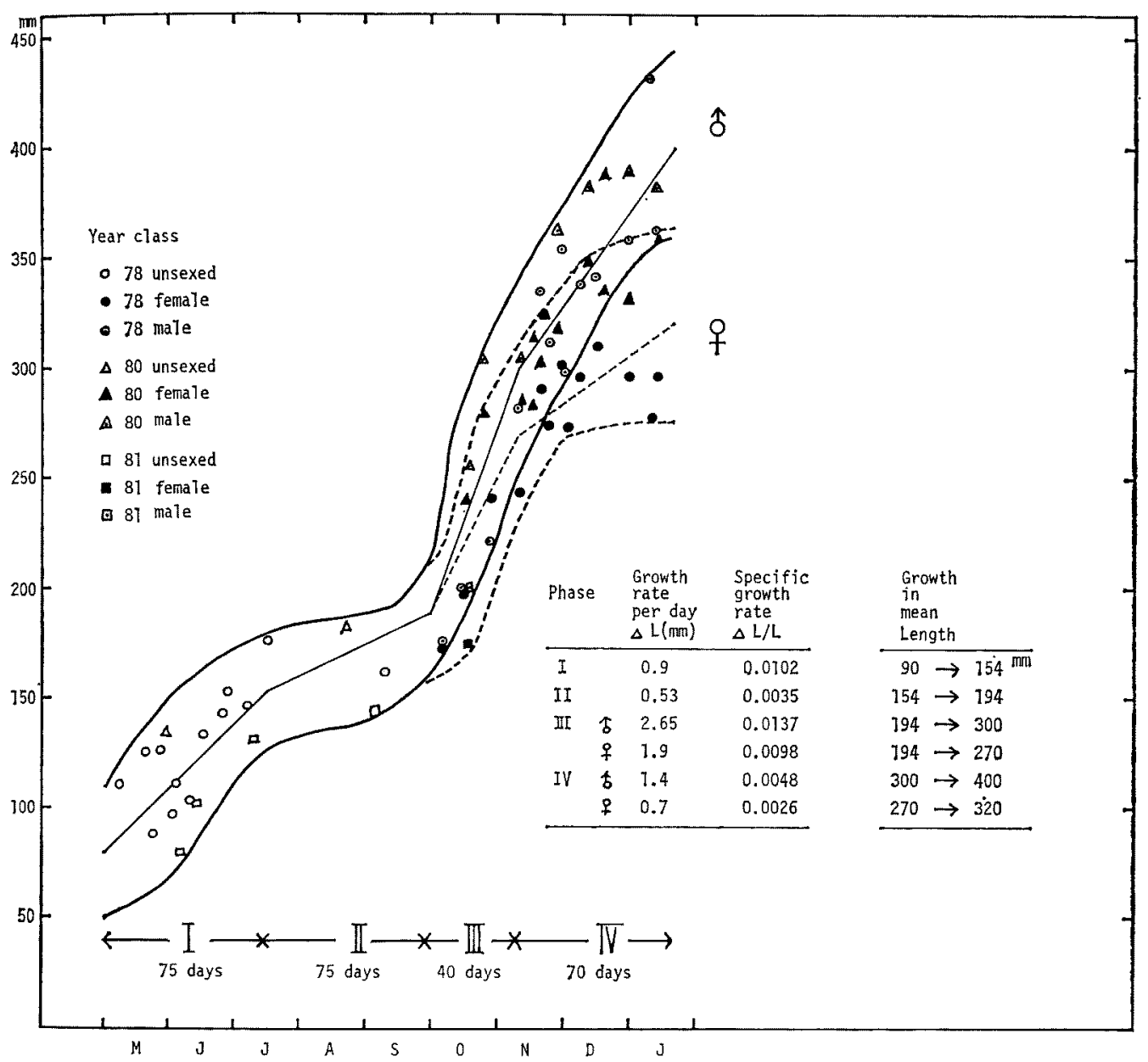

Fig. 2. Growth curves of snailfish in body length. Mark denotes mean length of a sample, discriminated by year classes. An undulating belt demarcated by solid curves shows growth of unsexed young fish and older male, with an intermediate series of straight lines as the growth pattern in average. Broken curves and lines correspond to the same for older female. Roman numerals along the bottom define particular phases of growth with their durations. Growth in mean length, growth rate and specific growth rate for each phase are also shown.

the period examined. However, if Fig. 4 is observed finely, we can find that the male's GSI curve has risen slightly on Nov. 28, 1980 like female and this situation remained unchanged.

In Fig. 4, vertical broken lines denote mean body length. GSI curves of both sexes move rightupwards with growth. Peaks of GSI curves of females are found around their mean body length.

Change of the size distributions of oocytes with increase in GSI for snailfish of 291-309 $\mathrm{mm}$ long is shown in Fig. 5. There are three size groups, Oocyte Groups (OGs) I, II, and III, in the advanc- ing order. Ova in OG III are those ovulated into the ovarian cavity. In this figure, histograms are depicted so as that egg number of Batch I and II and that of Batch III correspond to $100 \%$ respectively.

Ovaries of 5.3 to 13.9 in GSI (Fig. 5, $a$ to $c$ ) were in the immature state except for Batch III, while Batch II was growing with increase in GSI.

In an ovary of 15.4 in GSI (Fig. $5, d$ ), OG II grew up to become OG III, and the ovarian cavity was full of ovulated eggs. On the other hand, a part of OG I grew to form Batch II, resulting in a 


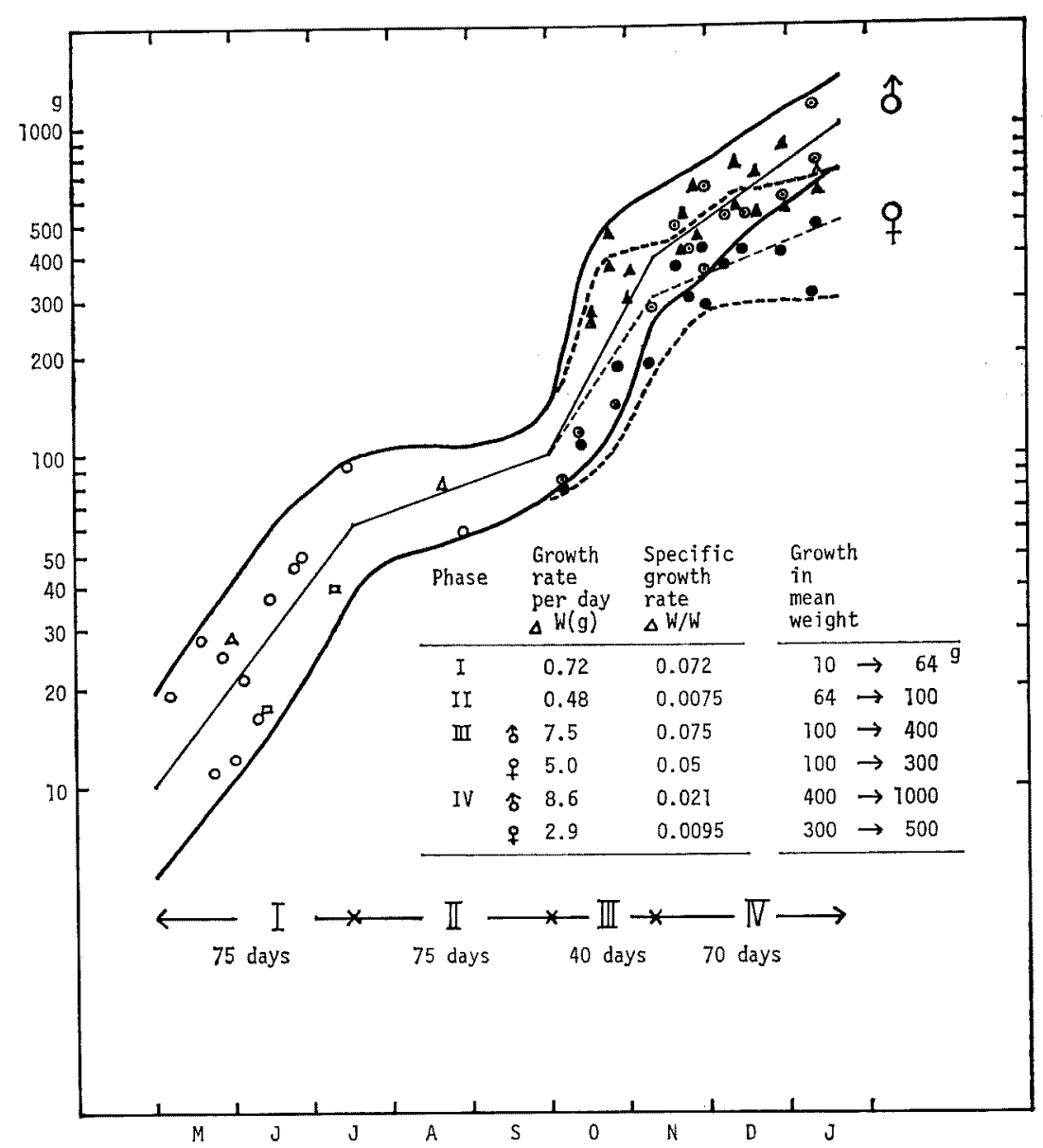

Fig. 3. Growth curves of snailfish in body weight. For explanation, see Fig. 2.

trimodal distribution of oocyte size in the ovary. Although GSI rose to a high level from $e$ to $f$ of Fig. 5, the trimodal pattern remained unchanged, with modes of egg size at 1.4 and $1.5 \mathrm{~mm}$.

In $g$ and $h$ of Fig. 5, GSI declined, while the trimodal distribution of ovum size remained unchanged, with a mode of Batch III at $1.5 \mathrm{~mm}$.

Numbers of the largest ova are shown in $c, d$, $e$ and $f$ of Fig. 5 , indicating a wide variation from 12000 to 28000 , in spite of a small variation in fish size from 291 to $309 \mathrm{~mm}$.

Regressions of the number of the largest ova (F) on the body length $L(\mathrm{~mm})$ are given below.

$$
\begin{array}{ll}
F=0.227 L^{1.925} & \text { for } 1978 \text { year class } \\
F=0.279 L^{1.838} & \text { for } 1980 \text { year class }
\end{array}
$$

The coefficient of correlation is significant only for 1978 year class (Fig. 6).

In Table 1, numbers of oocyte in each OG of six fish are shown. Three OGs are shown for a fish of $308 \mathrm{~mm}$ in this table, despite two batches of the same fish in Fig. 5 c. This results from that OG I in the figure consists of easily distinguishable two size groups different in development from each other. Therefore, OG $I$ in the figure is to be divided into OGs I and II in the table, while OG III in the table is to be assigned to OG II in the figure. A fish of $369 \mathrm{~mm}$ lacked OG III because its ovary remained in a growing stage. In Table 1 the value of total number of oocytes divided by the number of the largest ova is also shown to estimate the frequency of spawning.

\section{Discussion}

From the change in GSI in Fig. 5, the spawning of snailfish seems to be carried out in December and January, with its peak after late December 

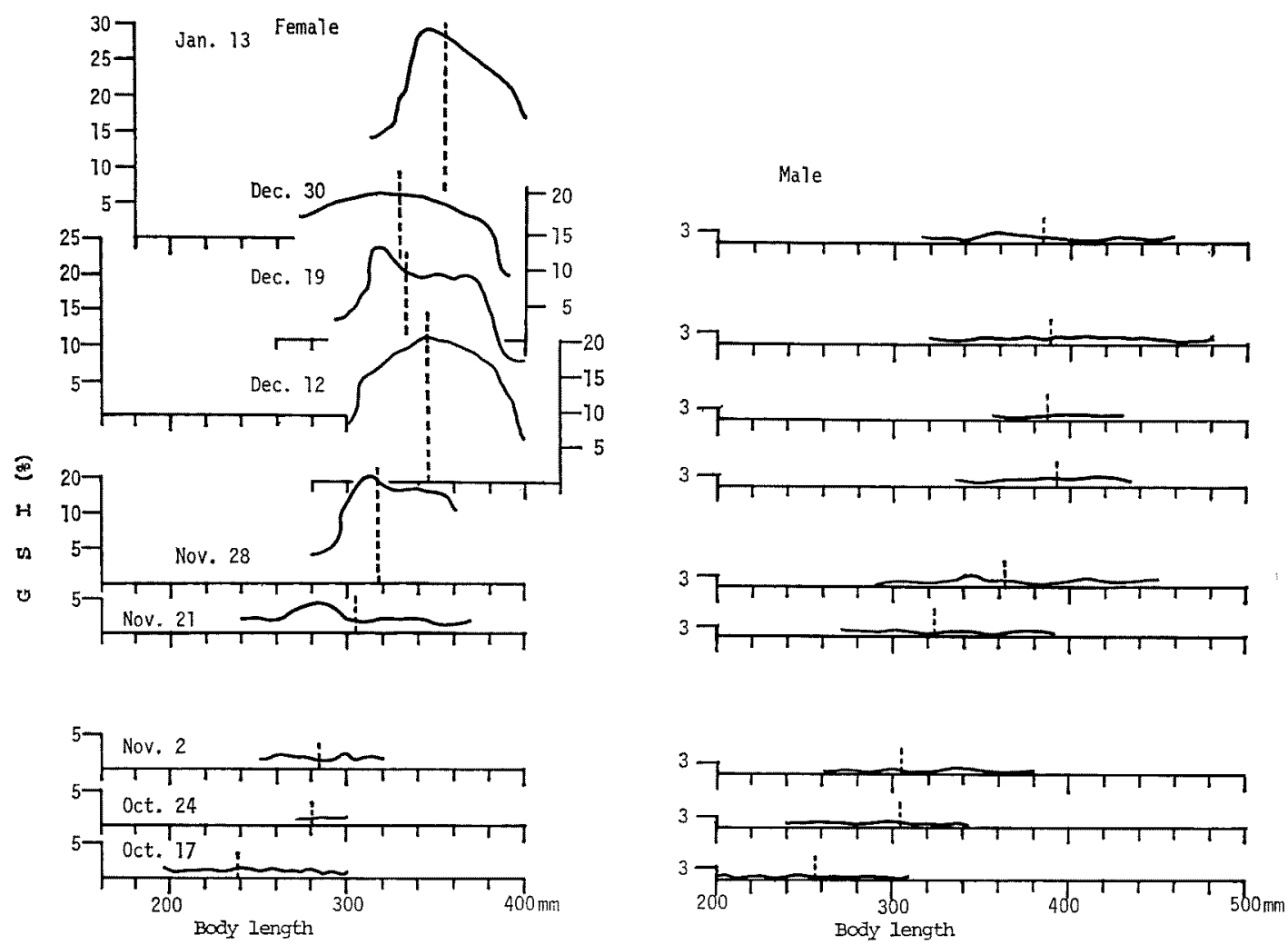

Fig. 4. Maximum GSI-on-length curve of samples for 1980 year class in advancing order from bottom to top. Vertical broken line denotes the mean body length.

Table 1. Number of oocytes of each $O G$ of samples

\begin{tabular}{ccccccccc}
\hline \multirow{2}{*}{$\begin{array}{c}\text { BL } \\
(\mathrm{mm})\end{array}$} & \multirow{2}{*}{$\begin{array}{c}\text { GSI } \\
(\%)\end{array}$} & \multicolumn{2}{c}{$\begin{array}{c}\text { Date of } \\
\text { collection }\end{array}$} & \multicolumn{2}{c}{ Number of oocytes } & & Sum & Sum/OG III \\
\cline { 4 - 7 } & & & OG I & OG II & OG III & & & \\
\hline 273 & 16.9 & Dec. 30, 1980 & 63854 & 13027 & 18131 & 95012 & 5.2 \\
303 & 17.3 & Dec. 19, 1980 & 70817 & 17373 & 14617 & 102807 & 7.0 \\
308 & 13.9 & Dec. 12, 1980 & 75336 & 32088 & 23672 & 131096 & 5.5 \\
366 & 13.3 & Jan. 13, 1981 & 120965 & 31412 & 15729 & 168106 & 10.7 \\
369 & 12.0 & Dec. 12, 1980 & 178457 & 33805 & - & 212262 & $6.3^{*}$ \\
396 & 16.9 & Jan. 13, 1981 & 88954 & 41620 & 40154 & 170728 & 4.3 \\
\hline
\end{tabular}

(Fig. 6).

As seen in Table 1, OG II is of size comparable to OG III for 4 specimens out of 5 , supposedly indicating that a part of immature oocytes has grown from OG I to II, all of which mature into OG III to be produced. A fish of $366 \mathrm{~mm}$ in Table 1 seems to have been in the process of spawning because of fewer oocytes of OG III than II. Table 1 also shows that the frequency of spawning of snailfish may be 5-7.
An ovary of the snailfish has two groups of yolky oocytes and eggs may be laid in 5-7 batches. Eggs from OG III or II seem to be produced simultaneously and Fig. 6 may give a relation between batch size and fish size, which varies from year class to year class. Since snailfish continue to feed and grow while carrying out spawning (see "Food Habits"), food intake and growth presumably influence their reproductive process. In the present study, since no snailfish that had produced all the 

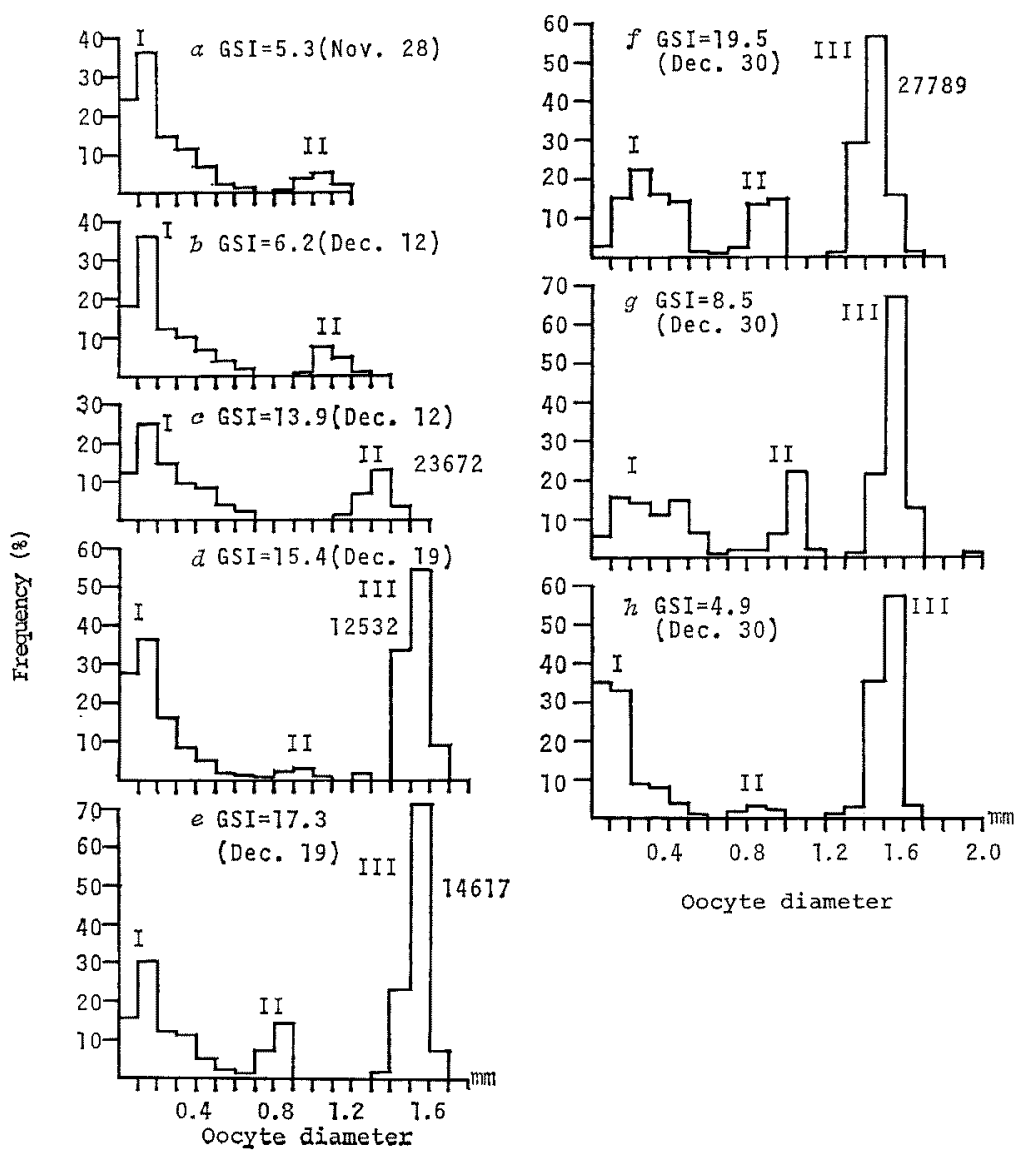

Fig. 5. Histograms of oocyte size distribution in advancing order of GSI, for snailfish of 291$309 \mathrm{~mm}$.

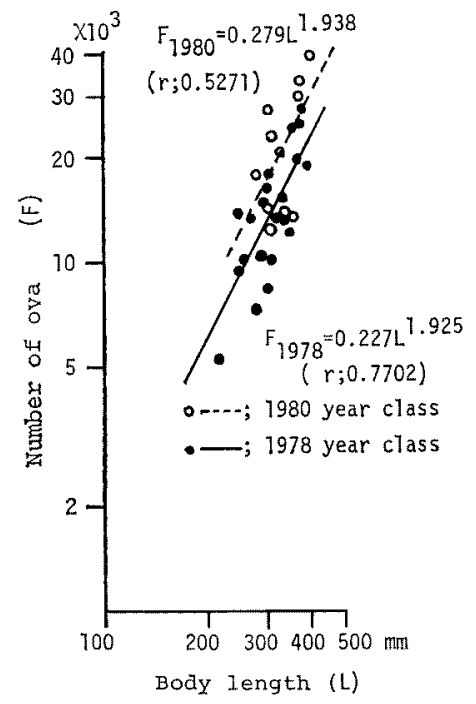

Fig. 6. Regression of number of ova in OG II or III on body length for 1978 and 1980 year classes. ova was found, it remained to be demonstrated whether all the ova are destined to be released.

The snailfish begin to mature in Phase III of the fastest growth (Fig. 2), which is also a period when sexual characters are disclosed. In Phase IV when growth is slowed down (Fig. 2), GSI of female rises to a high level of some $30 \%$, ten times more than that of male, and the difference in size between sexes becomes very large.

In conclusion, it can be said that Phase III is the period for the preservation of individual, while Phase IV is one for the preservation of brood.

\section{Food Habits}

\section{Materials and Methods}

Stomachs were removed from the abdominal cavity and preserved in 10 per cent formalin solution. Stomach contents were identified to the level of species. Number of organisms and over- 


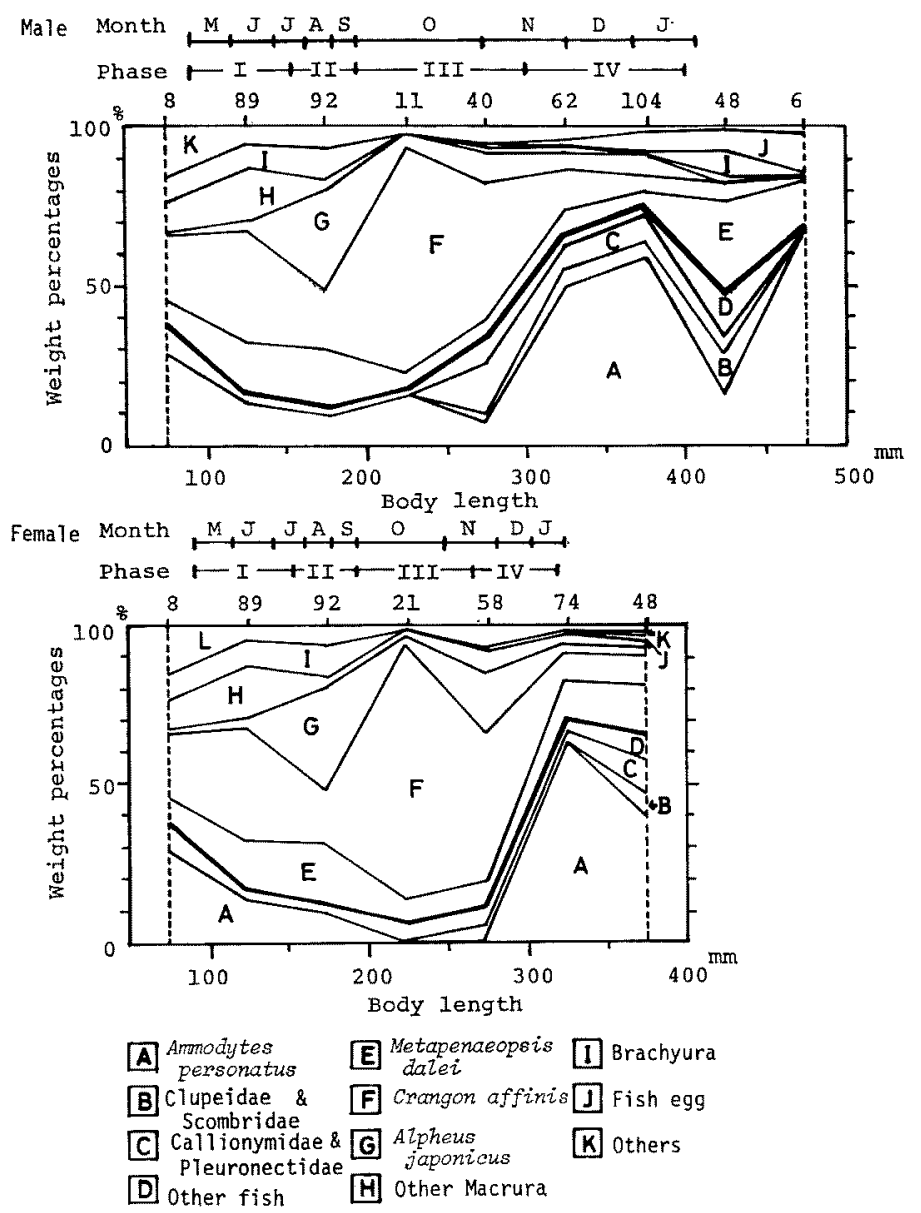

Fig. 7. Composition of food ingested in weight percentages in $50 \mathrm{~mm}$ body length intervals by sexes. Along the top horizontal line the number of stomachs investigated is indicated, along with the corresponding durations of the growth phase and month. Fishes (lower) and the others (upper) are demarcated by undulating bold line.

all weight of each species in a stomach and size (body length, body width and body weight) of ingested organisms were counted and measured.

\section{Results}

1. Food composition: Taxon compositions in weight percentages of food ingested in each $50 \mathrm{~mm}$ length interval for both sexes of snailfish show seasonal and qualitative change with development and growth (Fig. 7). The male as well as female snailfish shift their foods from crustaceans, mainly macrurans to fishes, mainly a sandeel Ammodytes personatus, when having exceeded $250 \mathrm{~mm}$ in body length during fast growing Phase III (Fig. 2) and reaching the adult stage.

2. Amount of food ingested: The plots of weight of food in a stomach on ordinate and body length of a snailfish on abscissa as well as the regression of the arithmetical mean of food weights in stomachs in every $50 \mathrm{~mm}$ length interval on mean length of fish within this interval, are shown in Fig. 8. Food weight in the stomach increases exponentially with development and growth as shown in Fig. 8. The change in average number of food organisms in a stomach with increasing length and the relation of their mean weight to the median of body length in each length interval are shown in Figs. 9 and 10 respectively. A rising trend in the number of food organisms in a stomach with size is converted to a falling beyond $250 \mathrm{~mm}$ in length for male (Fig. 9), clearly resulting from the change of food from crustacean to fish. 

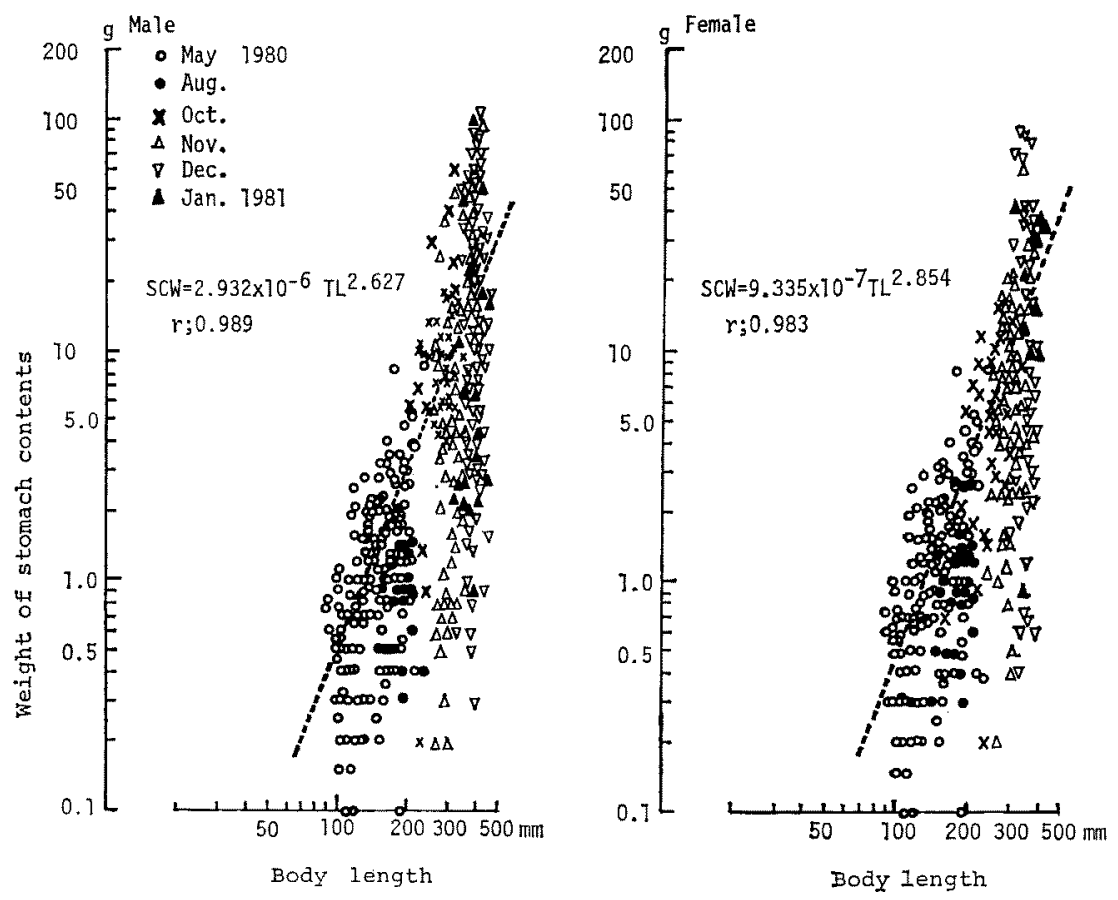

Fig. 8. Relation of weight of food in a stomach to body length in logarithmic scale by sexes. An oblique broken line denotes regression of mean value of the former to that of the latter.
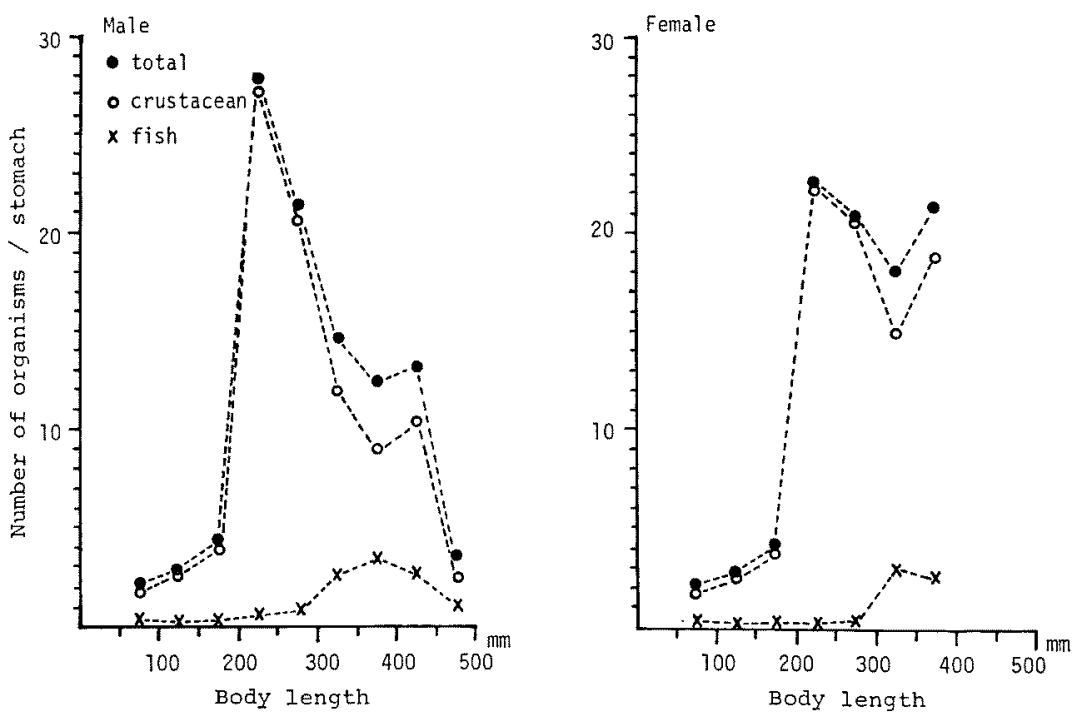

Fig. 9. Change in average number of organisms in a stomach with growth by sexes.

As seen in Fig. 10, although no marked change occurs in the mean weight of crustacean organisms in the stomachs of both sexes, a notable increase is observed in the weight of fishes taken by the snailfish over $200 \mathrm{~mm}$. We can see in Fig. 9, that the females under $250 \mathrm{~mm}$ show the same rising tendency as males in the number of food organisms in their stomachs with increasing length, but this 

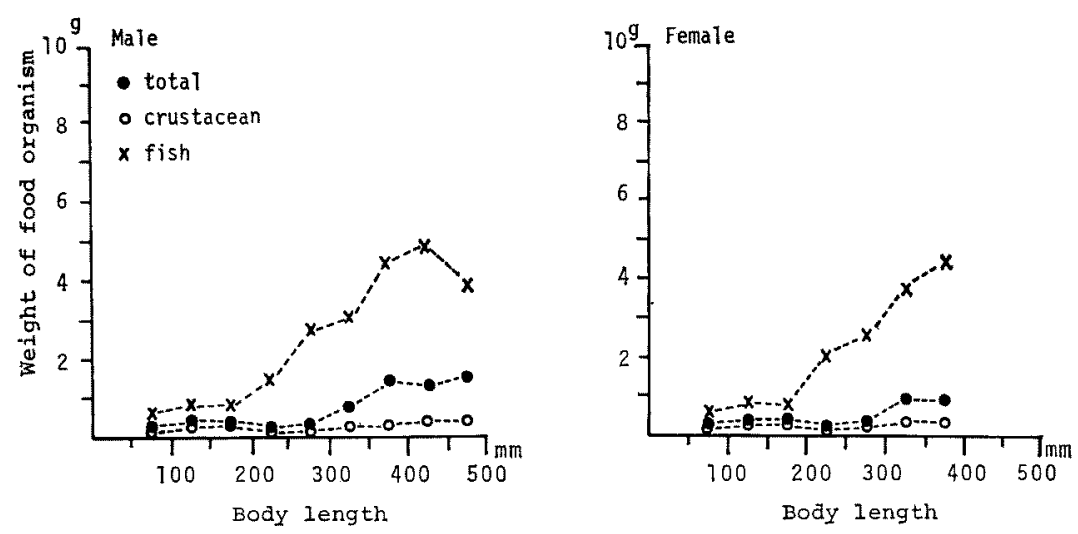

Fig. 10. Change in average weight of organisms in a stomach with growth by sexes.

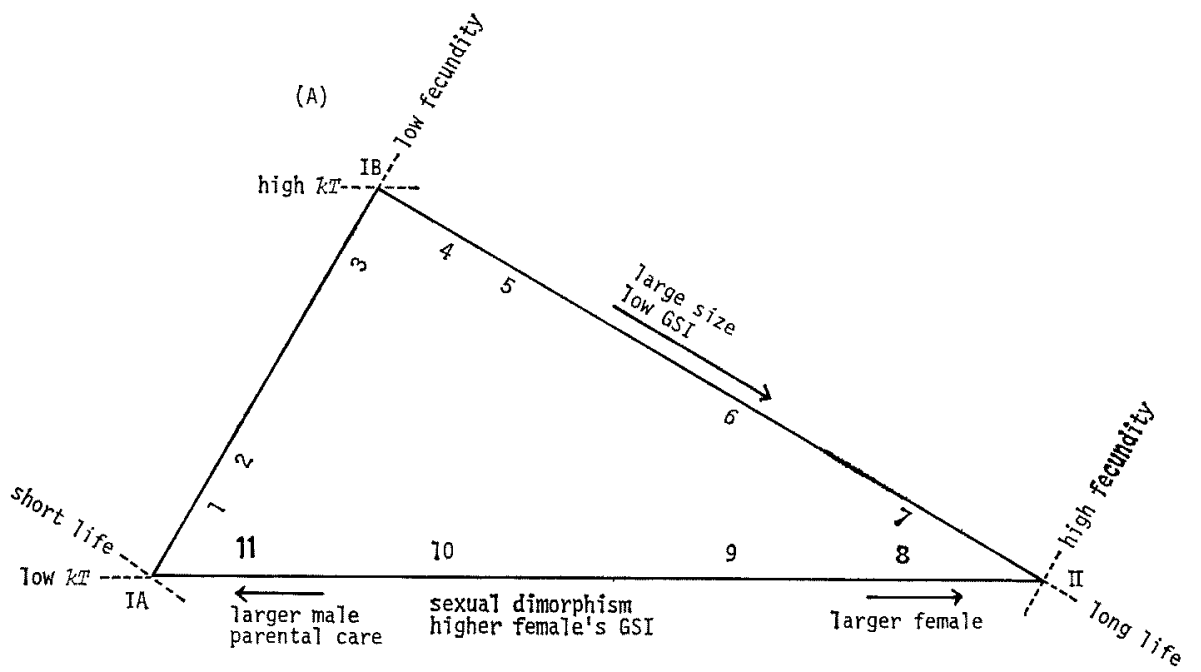

(B)

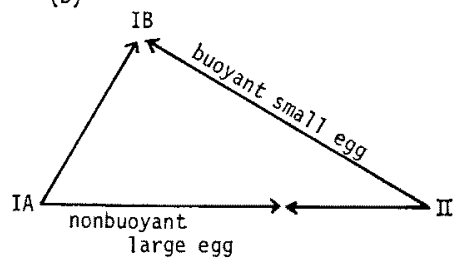

(C)

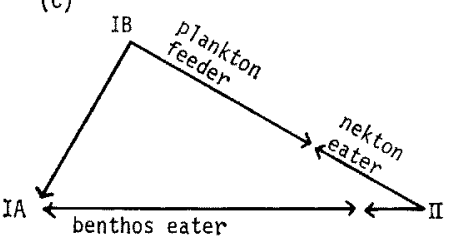

Fig. 11. Life historical triangle of the marine teleosts, from the viewpoint of three dimensions (A), nature of eggs $(B)$ and food habit $(C)$. Number inside the figure $(A)$ denotes locus of each taxon shown below. In (A) $k$ is the Bertalanffy's growth parameter and $T$ is the generation time.

1: saury, $2:$ sandeel, $3:$ herring, $4:$ sardine, $5:$ jack mackerel, $6:$ mackerel, $7:$ tunas, $8:$ heterosomes, $9:$ gadoids, $10:$ gobies, 11 : snailfish.

tendency becomes levelled off thereafter, indicating the effect of increase in the number of crustaceans caught by the young snailfish. 3. Incidence of empty stomachs: Empty (Table 2). stomachs of snailfish have kept a low level in proportion throughout their lives, except for a rise in male during spawning in December and January 
Table 2. The number of total (N) and empty (E) stomachs, arranged by length interval and month. Incidence of empty ones is given in parentheses following $\mathrm{E}$

\begin{tabular}{|c|c|c|c|c|c|c|c|c|c|c|c|c|c|}
\hline & \multirow{2}{*}{$\begin{array}{l}\text { Body length } \\
\text { class (mm) }\end{array}$} & \multicolumn{2}{|c|}{ May, 1980} & \multicolumn{2}{|c|}{ Aug. } & \multicolumn{2}{|r|}{ Oct. } & \multicolumn{2}{|r|}{ Nov. } & \multicolumn{2}{|r|}{ Dec. } & \multicolumn{2}{|c|}{ Jan., 1981} \\
\hline & & $\mathbf{N}$ & $\mathrm{E}(\%)$ & $\mathbf{N}$ & $E(\%)$ & $\mathbf{N}$ & $\mathrm{E}(\%)$ & $\mathbf{N}$ & $\mathrm{E}(\%)$ & $\mathbf{N}$ & $\mathrm{E}(\%)$ & $\mathrm{N}$ & $E(\%)$ \\
\hline \multirow[t]{9}{*}{ Male } & $50-99$ & 8 & 0 & & & & & & & & & & \\
\hline & $100-149$ & 87 & $3(3.4)$ & 5 & 0 & & & & & & & & \\
\hline & $150-199$ & 36 & 0 & 88 & $1(1.1)$ & & & & & & & & \\
\hline & $200-249$ & 2 & 0 & 18 & 0 & 11 & 0 & & & & & & \\
\hline & $250-299$ & & & & & 14 & 0 & 26 & 0 & & & & \\
\hline & $300-349$ & & & & & 17 & 0 & 29 & $1(3.4)$ & 10 & 0 & 6 & $1(16.7)$ \\
\hline & $350-399$ & & & & & 1 & 0 & 10 & 0 & 80 & $2(2.5)$ & 13 & $1(7.6)$ \\
\hline & $400-449$ & & & & & & & 1 & 0 & 42 & $3(7.1)$ & 5 & $1(20.0)$ \\
\hline & $450-499$ & & & & & & & & & 3 & 0 & 3 & 0 \\
\hline \multirow[t]{8}{*}{ Female } & $50-99$ & & & & & & & & & & & & \\
\hline & $100-149$ & & & & & & & & & & & & \\
\hline & $150-199$ & & & & & 3 & 0 & & & & & & \\
\hline & $200-249$ & & & & & 18 & 0 & 3 & 0 & & & & \\
\hline & $250-299$ & & & & & 15 & 0 & 42 & 0 & 1 & 0 & & \\
\hline & $300-349$ & & & & & 3 & 0 & 26 & 0 & 37 & 0 & 8 & 0 \\
\hline & $350-399$ & & & & & & & 4 & 0 & 37 & 0 & 8 & 0 \\
\hline & $400-449$ & & & & & & & & & 1 & 0 & & \\
\hline
\end{tabular}

\section{Discussion}

From the above results, we can generalize a pattern of food acquisition of the snailfish as below. Pattern of food acquisition is transformed through their lifetime from "number selection" in that requirement for food is provided by a great number of crustaceans, in particular macrurans, to "size selection" in that fewer large fishes, in particular sandeel, to meet the demand of the snailfish. This change occurs more drastically in the male than in the female and the change in the number of food organisms of the latter is not necessarily clear. Two factors seem to be responsible for causing the drastic shift in the food acquisition pattern; one is the temporal and spatial change in the food procurability viewed from the prey side and the other is the qualitative and quantitative change of the predators' physiological conditions. However, since data sufficient for discussing the former issue have not been available, the latter factor will be scrutinized below. It would be conceivably required for snailfish to procure the preys of optimal size for maximizing the gain as a difference between energy taken in and that expended in searching and catching food, under the conditions of rapid development and growth. A drastic change of food acquisition pattern at a particular developmental stage seems to meet this requirement. The conversion of "number selection" to "size selection" in the food acquisition pattern occurs during Phase III of the fastest growth when the food requirement rapidly increases, as shown by an exponential increase in stomach contents. This rise of food demand seems to be one and main driving force of the conversion. The conversion takes place a month prior to the rapid rise in GSI in late November, indicating that the snailfish has to prepare for reproduction by taking in more substances, and this seems to be another reason for the conversion. As seen in Fig. 8, food quantity similar to that for the male or more are taken by the female in spite of their low growth. This fact shows that the female must pour more energy into reproductive tissues than male, as testified by their higher GSI than male.

Empty stomachs for the male increase in proportion in the spawning season of December to January and a number of eggs are found in them, implying males care for eggs as referred to "Discussion".

\section{Discussion}

From the foregoings we can summarize the life historical traits of snailfish as below. The most marked characteristic of the life history of snailfish is their short life of one year. Consequently all developmental stages must be passed through within a year, resulting in that change in the life cycle is completely overlapped with the sequence of developmental stages. This fact corresponds to a drastic shift of the food acquisition pattern of 
snailfish in transition from Phase II to Phase III of growth (the second feature). The third feature is a remarkable sexual dimorphism in that the male grow larger than female and the fourth is to lay eggs larger and fewer among the marine teleosts.

Let us examine the adaptive significance of the life histories referred to above. The fundamental strategy for survival of snailfish is to raise the intrinsic rate of natural increase $r$ in order to regulate their population finely. Maximum $r, r_{m}$, is expressed as

$$
r_{m} \fallingdotseq \ln \left(\sum l_{x} m_{x}\right) / T
$$

where $l_{x}$ is the probability at age 0 to surviving to age $x, m_{x}$ is the number of female eggs laid by the average female in the age interval $(x-0.5)$ to $(x+$ 0.5 ) and $T$ is cohort generation time, mean age of mothers in cohort at birth of female offspring. Snailfish assume the strategy to lessen $T$ to a value as short as possible (here $T$ equals unity) and increase $l_{x}$ (here only $x=1$ is possible) so that $r_{m}$ can take a high value in spite of low $m_{x}$. This is the strategy approaching Subtype IA (Fig. 11) that allocates more energy for reproduction.

A life history to produce large nonbuoyant massed eggs cared for by large male has been selected in snailfish. According to ABLE and MCAlLISTER ${ }^{4)}$ the female of another snailfish $L$. atlanticus distributed along the Atlantic coast of northern North America has deposited small batches several times which the male fertilizes, gathers into a single attached egg mass and hides among stones and algae. Perhaps the male continues to look after this egg mass. In order to care for eggs effectively the male must have become stronger and larger. Although it superficially appears that the larger male would contradict allocation of more energy to reproduction, this could mean the same effect as high fecundity resulting from assigning more substance to the female, because more eggs might survive, not suffering from damages like predation. Such a watching behavior is observed in case of a goby Pterogobius elpodes (Dotsu and TSUTSUMI ${ }^{b)}$ ).

We intend to revise a part of life historical triangle set forth by KAWASAKI, ${ }^{3)}$ based on the present work (Fig. 11 (A)).

(1) Although in the life historical triangle Side IAII represents sexual dimorphism, only an arrow toward Vertex II indicating that the female becomes larger than male is shown in the former paper. This is a direction to the heterosomes that live long and lay a large number of small eggs. This time we add another oppositely directed arrow toward IA showing that the male becomes larger than the female. This is a direction toward snailfish and some gobies which are short-lived and produce a small number of large eggs cared for by their fathers. Along Side IAII the nearshore and demersal fishes occupy their positions, while a domain from IA to II by way of IB is occupied by the pelagic fishes. Over Side IAII GSI is higher in female than male because the males of the nearshore or demersal fishes are able to fertilize eggs more efficiently through various measures than the pelagic fishes that spawn in the open surface or subsurface layers. On the other hand, saury Cololabis saira, a species close to IA, occupies a position along Side IAIB, because this fish is a pelagic swimmer and hardly reveal sexual dimorphism.

(2) A part from Vertex IB halfway to II by way of IA is a domain occupied by species depositing demersal large eggs, while that from IB halfway to IA via II is one occupied by fishes laying pelagic small eggs. Therefore, the sardines Sardinops and herrings Clupea, both occupying loci close to IB, are located along Side IBII and Side IBIA respectively (Fig. 11 (B)).

(3) Incidentally, benthos eaters are located between IA and a point a little apart from II. From the latter point to one close to II on the way from II toward IB the nekton eaters are located (Fig. 11 (C)). Among the benthos and nekton eaters interspecific competition for food is keen. This is a domain efficient in food utilization and low in biological production. On the contrary, a part from IA to a point near II by way of IB is occupied by the plankton feeders where inter specific relations for food is lax. This is an inefficient and productive domain.

\section{References}

1) T. Aoxama: Bull. Seikai. Fish. Res. Lab., 18, 69-73 (1959).

2) M. KosaKa: J. Coll. Mar. Sci. Tech. Tokai Univ., 5, 27-41 (1971).

3) T. KAWASAKI: Bull. Japan. Soc. Sci. Fish., 46, 289-293 (1980).

4) K. W. Able and D. E. McAllister: Can. Bull. Fish. Aqua. Sci., 208, 1-52 (1980).

5) Y. Dotsu and T. Tsutsumr: Rep. Fac. Fish. Nagasaki Univ., 8, 186-192 (1959). 